\title{
Notes
}

\section{A Proposal for Measuring Underrepresentation in the Composition of the Jury Wheel}

\author{
Peter A. Detre
}

\section{INTRODUCTION}

In most jurisdictions in the United States, the first step in choosing a jury is to compile a master list of potential jurors. This list is usually drawn from voter registration rolls, sometimes supplemented by other sources. People on the master list who are statutorily eligible are then added to the so-called qualified jury "wheel" or "pool." Panels of grand or petit jurors are chosen from the jury wheel, usually at random. Courts and commentators have considered various "measures"2 to determine whether the underrepresentation of a given group on a jury wheel rises to a level that might require redress. Yet none of these measures seems to reflect accurately the extent to which the defendant's constitutional and statutory rights have been undermined by the underrepresentation. This Note proposes a new measure.

There are two main routes to challenging the composition of a jury wheel. First, a defendant may allege that the wheel does not represent a "fair crosssection" of the community as required by the Sixth Amendment's guarantee of trial by "an impartial jury of the state and district wherein the crime shall

1. Potential jurors may be disqualified for any of a number of reasons, depending on the jurisdiction. For example, police officers, convicted felons, or those over a specified maximum age are often disqualified. See generally JON M. VAN DYKE, JURY SELECTION PROCEDURes (1977).

2. This Note uses the term "measure" to denote a way of measuring underrepresentation. The term "test" is reserved for a legal standard that incorporates a measure. 
have been committed." 3 This fair cross-section requirement has also been codified in the Jury Selection and Service Act of 1968 (JSSA). ${ }^{4}$ Although the JSSA does not apply to state courts, the Sixth Amendment guarantee does, through the due process clause of the Fourteenth Amendment. ${ }^{5}$ Second, the defendant may bring an equal protection challenge, ${ }^{6}$ under either the Fourteenth Amendment for state juries or the due process clause of the Fifth Amendment for federal juries. ${ }^{7}$

In order to prevail in either a fair cross-section or equal protection challenge, a defendant must show that the underrepresentation of the group in question is, in some sense, "substantial." Whether or not the underrepresentation is found to be substantial depends, in part, on the measure chosen by the court to gauge underrepresentation. None of the measures that courts have employed addresses the degree to which the defendant's ex ante chances of drawing an unrepresentative jury have increased as a result of the underrepresentation on the wheel. Consequently, each can lead to anomalous results: showing a greater degree of underrepresentation in situations in which the defendant's chances have been affected to a lesser degree, and vice versa. In particular, the two measures used most frequently in fair cross-section challenges tend to underestimate the degree to which the defendant's chances have been affected, leading to dismissal of challenges for failure to establish a prima facie case even though the defendant's chances of drawing a representative jury have been substantially undermined.

Part II of this Note describes the elements of jury wheel composition challenges under the fair cross-section and equal protection theories and explores the measures courts have applied to determine whether the underrepresentation of a particular group on the jury wheel is substantial. Part III surveys the relevant case law, focusing on the various measures courts have chosen to test for underrepresentation and the rationales behind these choices. This Note argues that the increasing use of different measures in equal protection versus fair cross-section cases is a symptom of confusion on the part

3. Taylor v. Louisiana, 419 U.S. 522, 529-30 (1975).

4. 28 U.S.C. $\$ \$ 1861-1869$ (1988) ("[A]ll litigants in Federal courts entitled to trial by jury shall have the right to grand and petit juries selected at random from a fair cross-section of the community."); see United States v. Miller, 771 F.2d 1219, 1227 (9th Cir. 1985) ("The test for a constitutionally selected jury is the same, whether challenged under the Sixth Amendment of the Constitution or under the Jury Selection and Service Act.").

5. Duncan v. Louisiana, 391 U.S. 145, $147-49$ (1968). While the JSSA applies to grand and petit juries, the Sixth Amendment applies only to petit juries. Thus, arguably, a defendant in a state court has no federal constitutional right to a grand jury representing a fair cross-section of the community. See Barbara D. Underwood, Ending Race Discrimination in Jury Selection: Whose Right Is It, Anyway?, 92 COLUM. L. REV. 725, 737-38 (1992).

6. Whether the defendant must be a member of the allegedly underrepresented group, and the related question of whether the defendant is asserting his own constitutional rights or those of the group, has been a subject of some controversy. See infra note 58.

7. Bolling v. Sharpe, 347 U.S. 497, 499 (1954) (holding that due process clause of Fifth Amendment contains equal protection component). 
of the courts. There is no reason to apply different criteria in testing for substantial underrepresentation in the two contexts. Part IV argues that none of the measures courts have applied accurately reflects the degree to which a defendant's right to a jury chosen from a fair cross-section of the community has been undermined by underrepresentation on the wheel. It maintains that an appropriate test would measure the degree to which the defendant's ex ante chances of drawing an unrepresentative jury have increased. Finally, in Part V, this Note offers a new measure- "disparity of risk"-that precisely reflects the change in the defendant's ex ante chances of drawing a representative jury. In other words, it measures the increased risk that the defendant will draw an unrepresentative jury and for this reason it precisely captures the concerns behind the fair cross-section guarantee. Disparity of risk correctly measures the degree to which the defendant's chances of a representative jury have been undermined by the underrepresentation of a group on the jury wheel. Hence, a test that incorporated disparity of risk would lead to success in jury composition challenges that courts today generally would deny for failure to establish a prima facie case.

\section{BACKGROUND TO JURY WHEEL COMPOSITION CHALLENGES}

The Supreme Court's statement of the law governing equal protection and fair cross-section challenges to the composition of a jury wheel can be found in two cases from the late 1970 's. In Castaneda v. Partida ${ }^{8}$ the Court established the test for equal protection challenges. Although the language of Castaneda is not entirely clear, later decisions have interpreted it as a threepronged test which, if satisfied, creates a presumption of intentional discrimination in equal protection cases. ${ }^{9}$ In order to make out a prima facie case, the defendant must prove:

(1) that the group to which he belongs "is a recognizable, distinct class, singled out for different treatment under the laws, as written or as applied", 10

(2) that "the degree of underrepresentation [is substantial] by comparing the proportion of the group in the total population to the proportion called to serve as grand jurors, over a significant period of time", 11 and

\footnotetext{
8. 430 U.S. 482 (1977).

9. See Alston v. Manson, 791 F.2d 255, 257 (2d Cir. 1986), cert. denied, 479 U.S. 1084 (1987). But see United States v. Biaggi, 909 F.2d 662, 677 n.4 (2d Cir. 1990) (questioning whether third "prong" of Castaneda is required for prima facie case), cert. denied, 499 U.S. 904 (1991).

10. Id. at 494 .

11. Id.
} 
(3) that the "selection procedure ... is susceptible of abuse or is not racially neutral," which the Court stated, "supports the presumption of discrimination raised by the statistical showing."12

If the defendant establishes the elements of the prima facie case, the burden then shifts to the state "to dispel the inference of intentional discrimination."13

In Duren v. Missouri, ${ }^{14}$ the Supreme Court stated a similar three-pronged test to establish prima facie violations to the composition of a jury wheel under the Sixth Amendment's fair cross-section guarantee, holding that the defendant must prove:

(1) that the group alleged to be excluded is a "distinctive" group in the community; (2) that the representation of this group in venires from which juries are selected is not fair and reasonable in relation to the number of such persons in the community; and (3) that this underrepresentation is due to systematic exclusion of the group in the jury-selection process. ${ }^{15}$

If the defendant establishes the prima facie case, the burden then shifts to the state to justify "this infringement by showing attainment of a fair cross-section to be incompatible with a significant state interest."

The Duren test's three prongs seem roughly to correspond to those of the Castaneda test, but since intentional discrimination need not be shown for Sixth Amendment or JSSA challenges, conventional wisdom has it that defendants will find it easier to prevail in fair cross-section cases. ${ }^{17}$ Nevertheless, defendants continue to bring equal protection challenges,${ }^{18}$ in part because some courts have imposed different mathematical criteria for what constitutes sufficient underrepresentation to make out a prima facie case in equal protection cases as opposed to fair cross-section cases. ${ }^{19}$ Thus, despite the additional requirement of discriminatory intent, equal protection challenges may succeed in certain situations where fair cross-section challenges would fail.

12. Id.

13. Id. at $497-98$.

14. 439 U.S. 357 (1979).

15. Id. at 364 .

16. Id. at 368 .

17. See Laurie Magid, Challenges to Jury Composition: Purging the Sixth Amendment Analysis of Equal Protection Concepts, 24 SAN DiEGo L. REv. 1081, 1090-91 (1987) (Sixth Amendment requirements are easier to meet because it is unnecessary to show intent and because membership in the excluded group is not required for standing).

18. Prior to 1968, the rationale behind such challenges was clear: the Sixth Amendment had not yet been made applicable to the states through the Fourteenth Amendment. An equal protection challenge was at that time the only way that a state court defendant could press a jury composition challenge in federal court. While this rationale may still apply in the case of a defendant challenging a state grand jury panel, see supra note 5 , equal protection arguments continue to be raised by defendants challenging petit jury and federal grand jury panels.

19. See infra text accompanying notes 54-67. 
The second prongs of the Castaneda and Duren tests both require a showing that the underrepresentation in question is in some sense substantial enough to make out part of a prima facie case. This immediately raises two questions: first, how should underrepresentation be measured, and second, what level of underrepresentation, according to whatever measure has been chosen, is to be considered substantial? This Note will concentrates on the first question, though the second is discussed briefly in Part $\mathrm{V}^{20}$

Courts have looked to four different mathematical measures to determine whether the second prong of the Duren or Castaneda test has been satisfied, i.e., whether the degree of underrepresentation is sufficiently large. ${ }^{21}$ These measures are generally referred to as "absolute disparity," "absolute impact," "relative" or "comparative" disparity, and "statistical significance" or "statistical decision theory."

In order to calculate the absolute disparity between a group's representation in the population and its representation on the jury wheel, one simply subtracts the latter percentage from the former. ${ }^{22}$ Thus, if a group forms $10 \%$ of the population as a whole, but accounts for only $6 \%$ of the jury wheel, the absolute disparity is four percentage points. ${ }^{23}$

The second measure, absolute impact, is calculated by multiplying the absolute disparity by the size of the panel in question. One can think of the result as the number of jurors from the group excluded from the average panel. For example, the absolute impact on a grand jury of twenty-three corresponding to an absolute disparity of four percentage points would be .92 $(.04 \times 23)$, or slightly less than one person.

Comparative disparity is calculated by dividing the absolute disparity by the percentage of the group in the overall population and then multiplying by

20. See infra pp. 1936-37.

21. See generally Sara S. Beale, Integrating Statistical Evidence and Legal Theory To Challenge the Selection of Grand and Petit Jurors, LAW \& CONTEMP. PROBS., Autumn 1983, at 269; David Kairys et al., Jury Representativeness: A Mandate for Multiple Source Lists, 65 CAL. L. REv. 776 (1977); Martha Stone, Grand Jury Discrimination Challenges: Defeat by Default, 3 W. NEW ENG. L. REv. 665 (1981); Cynthia A. Williams, Note, Jury Source Representativeness and the Use of Voter Registration Lists, 65 N.Y.U. L. REV. 590 (1990).

22. With absolute disparity, as with all the other measures, there is a question of whether to compare the percentage of group members on the wheel with the percentage of the group in the adult population of the community or with the percentage of the group in the segment eligible for jury service. This question is of some practical importance because the former figure is easily obtainable from census data, whereas the latter may be difficult to estimate. In Castaneda and Duren, the Supreme Court endorsed the use of census data, although three Justices dissented from the Castaneda decision on this point. Castaneda v. Partida, 430 U.S. 482, 504 (1977) (Burger, C.J., dissenting). Lower courts have not always followed suit. See United States v. Brummitt, 665 F.2d 521, 529 (5th Cir. 1981) ("[T]he disparity . . . must be based not on total population but, instead, on those of the identifiable class who are eligible to serve as jurors."). Given the difficulty of obtaining reliable data concerning the eligible population, it seems reasonable to use the census data unless there is some evidence that the jury-eligible community is substantially different. For our purposes, the issue is not an important one-it is irrelevant to the method chosen to measure underrepresentation.

23. To avoid any ambiguity, this Note will adhere to convention referring to difference of percentages in terms of "percentage points" rather than using the symbol "\%." 
$100 \%$. The comparative disparity in the above example of a group comprising $10 \%$ of the community and $6 \%$ of the jury wheel is $40 \%((4 \% / 10 \%) \times 100 \%)$. In effect, comparative disparity imagines how many members of the group in question would be on the wheel if there were full representation, and then calculates the percentage decrease from this figure due to the underrepresentation. Another way to think of the comparative disparity is as the percentage decrease in the probability that someone in the underrepresented group will be selected for the jury wheel due to the underrepresentation. ${ }^{24}$

The fourth and most sophisticated measure is often referred to as statistical decision theory (SDT). ${ }^{25}$ SDT calculates the probability that the observed underrepresentation of the group on the jury wheel was the result of chance. If this probability is sufficiently small, then the second prong of the Duren or Castaneda tests could be met. The probability, which depends on the size of the wheel, is generally calculated by using the binomial distribution. ${ }^{26}$

\section{THE CURRENT DisarRaY of the CASE LAW}

There is a great deal of confusion about which measure is appropriate to determine whether the degree of underrepresentation is sufficient to establish a prima facie case in both the fair cross-section and equal protection contexts. Courts have variously applied all four measures, resulting in unpredictable outcomes. In large part, the confusion is due to the lack of a clear directive from the Supreme Court on how to gauge underrepresentation. Once a measure

24. See D.H. Kaye, Statistical Analysis in Jury Discrimination Cases, 25 JURIMETRICS J. 274, 278-79

25. See Michael O. Finkelstein, The Application of Statistical Decision Theory to the Jury Discrimination Cases, 80 HARV. L. Rev. 338 (1966).

26. The assumption that the random variable in question, the number of group members chosen, has a binomial distribution is justified if the size of the community and the group within the community are sufficiently large so that the percentage of the group in question does not vary significantly as the jury wheel is being chosen. If this condition does not hold, the hypergeometric distribution should be used instead. See MiCHAEL O. FINKELSTEIN \& BRUCE LEVIN, STATISTICS FOR LAWYERS 133-37 (1990).

Using the binomial distribution, if $n$ random selections are made from a population in which the proportion of a target group is a constant, $p$, then the probability that exactly $i$ members of the target group will be chosen is given by:

$$
\left(\begin{array}{l}
n \\
i
\end{array}\right) p^{i}(1-p)^{n-i}
$$

Id. at 111-12. The "binomial coefficient," $\left(\begin{array}{l}n \\ i\end{array}\right)$, represents the number of ways that $i$ objects can be chosen from $n$ objects. To calculate the probability, $P$, that $m$ or fewer members of the target group will be chosen, simply sum the probabilities that exactly $i$ members will be chosen as $i$ runs from 0 up to $m$, i.e.,

$$
P=\sum_{i=0}^{m}\left(\begin{array}{l}
n \\
i
\end{array}\right) p^{i}(1-p)^{n-i}
$$

Id. at 112 . 
is chosen, the question of where to draw the substantial underrepresentation line remains-and here again, there has been little guidance from the Court.

In Castaneda, the Court noted that an absolute disparity of forty percentage points was sufficient to make out a prima facie case in an equal protection challenge, citing various precedents in which the Court had applied the absolute disparity test and found lower disparities to be substantial. ${ }^{27}$ But the Court also included a long footnote describing statistical significance and implying that its application to the case was an additional factor in the holding that a prima facie case of discrimination existed. ${ }^{28}$

The language of the test in Duren-that the representation of the group "is not fair and reasonable in relation to the number of such persons in the community"29-could suggest either comparative disparity or absolute disparity. In actually applying the test, however, the Court merely relied on the difference between the percentage of women in the community (slightly over $50 \%$ ) and the percentage on the jury wheel $(15 \%)$ and noted that this discrepancy is sufficient to establish the second prong of the prima facie case. While not explicitly endorsing any of the mathematical tests, the Court seems to have considered only absolute disparity.

Between Castaneda and Duren, support can be found for applying any of three mathematical tests. The Court itself apparently applied absolute disparity in both cases, but did not indicate what minimum level of absolute disparity was required to establish a prima facie case. Neither did the Court consider what might be a sufficiently high level of comparative disparity, or a sufficiently low probability that the jury wheel was not the result of a random draw. As far as statistical significance is concerned, the Castaneda Court noted that "if the difference between the expected value and the observed number is greater than two or three standard deviations, then the hypothesis that the jury drawing was random would be suspect to a social scientist," indicate any equivalence between prima facie cases and suspicious social

27. 430 U.S. at $495-96$.

28. Id. at 496 n.17. Courts have disagreed over the holding of Castaneda. Compare United States v. Maskeny, 609 F.2d 183, 190 (5th Cir.) (stating that Castaneda was based on absolute disparity), cert. denied, 447 U.S. 921 (1980) with Moultrie v. Martin, 690 F.2d 1078, 1082 (4th Cir. 1982) (holding, based on Castaneda, that statistical significance test must be applied in equal protection jury challenge). The Castaneda footnote continues the Court's practice of relegating discussions of statistical significance to footnotes in equal protection cases. See, e.g., Alexander v. Louisiana, 405 U.S. 625, 630 n.9 (1972); Whitus v. Georgia, 385 U.S. 545, 552 n.2 (1967).

29. Duren v. Missouri, 439 U.S. 357,364 (1979) (emphasis added).

30. 430 U.S. at 496 n.17. The standard deviation of a random variable is a measure of its dispersion about its mean. If a random variable has the binomial distribution, see supra note 26 , the standard deviation

is given by $\sqrt{n p(1-p)}$. The statistical significance, or unlikelihood of the observed underrepresentation having occurred as a result of random selection, can be expressed as the number of standard deviations between the actual number of group members on the wheel and the expected number for a random selection. The greater the number of standard deviations, the less likely that the underrepresentation could have resulted from a random selection. 
scientists. In fact, the Court noted that in Castaneda the difference was approximately twenty-nine standard deviations.

Nor has the Court considered whether different mathematical tests might be appropriate in equal protection and fair cross-section challenges. The Court remarked in Duren that the two types of challenges are "not entirely analogous," ${ }^{31}$ but the only differences it mentioned were the requirement of "discriminatory purpose" in equal protection cases and the different sorts of rebuttal evidence that would be relevant. The Court apparently assumed that the two sorts of cases are analogous so far as the second prong of the prima facie tests (the degree of underrepresentation) is concerned, and consequently, that the same type of mathematical evidence would be relevant. ${ }^{32}$

\section{A. Fair Cross-Section}

The majority of courts have looked to absolute disparity or absolute impact standards to determine whether underrepresentation of a group is substantial for purposes of the fair cross-section guarantee. ${ }^{33}$ In United States $v$. Jenkins, ${ }^{34}$ the Second Circuit summed up the rationale behind this choice. African-Americans made up $5.45 \%$ of the community but only $3.3 \%$ of the jury wheel. The court found that the resulting absolute disparity of 2.15 percentage points did not amount to substantial underrepresentation. Adopting the absolute impact test, the court noted that correcting for an absolute disparity of 2.15 percentage points would amount to an addition of only one African-American to an average venire of sixty persons. As the court stated, "a difference of one (1) Negro in a panel of 60 jurors is not substantial." 35 The correct question where the Sixth Amendment and the JSSA are concerned is whether the defendant's right to trial by a jury "selected at random from a fair

\footnotetext{
31. 439 U.S. at 368 n.26.

32. See Maskeny, 609 F.2d at 190 (holding that same disparity must be shown in equal protection and Sixth Amendment cases).

33. See, e.g., United States v. Rodriguez, 776 F.2d 1509, 1511 (11th Cir. 1985) (holding that absolute disparity that does not exceed 10 percentage points is insufficient for prima facie case); United States $v$. Tuttle, 729 F.2d 1325, 1327 (11th Cir. 1984) (same); United States v. Hafen, 726 F.2d 21, 23-24 (1st Cir.) (holding 2.02 percentage point absolute disparity insufficient for prima facie case), cert. denied, 466 U.S. 962 (1984); United States v. Clifford, 640 F.2d 150, 155 (8th Cir. 1981) (holding 7.2 percentage point absolute disparity insufficient because it does not meet the 10 percentage point mark mentioned as not necessarily sufficient for a prima facie case in Swain v. Alabama, 380 U.S. 202, 208-09 (1965)); United States v. Potter, 552 F.2d 901, 905-06 (9th Cir. 1977) (holding that disparity that would, on average, add less than one person to a 23-person grand jury was not substantial); United States v. Test, 550 F.2d 577, 587 (10th Cir. 1976) (holding 4 percentage point absolute disparity insufficient because less than 10-16 percentage point absolute disparity standard in Swain); United States v. Goff, 509 F.2d 825, 826 (5th Cir.) (holding absolute impact of 1.4 grand jurors not substantial), cert. denied, 423 U.S. 857 (1975); United States v. Armsbury, 408 F. Supp. 1130, 1136 (D. Or. 1976) (holding that "substantial" underrepresentation implies more than one person per 12 person jury on average).

34. 496 F.2d 57 (2d Cir. 1974), cert. denied, 420 U.S. 925 (1975).

35. 496 F.2d at 66 .
} 
cross-section of the community"36 has been violated. Since there was no constitutional or statutory guarantee of "precise proportional representation of minority groups on grand or petit jury panels, ${ }^{, 37}$ one African-American more or less on a panel of sixty could hardly be said to deprive the defendant of a fair cross-section. In rejecting comparative disparity, the court found, in effect, that the fact that members of the African-American community had signicantly reduced chances of being called for jury service was not relevant to the question of whether the defendant's rights had been violated.

This reasoning leading to either the absolute disparity or absolute impact measure is initially somewhat persuasive, although this Note will conclude otherwise. ${ }^{38}$ Common sense seems to argue that a sufficiently small difference in the number of members of a particular group on a defendant's venire is unlikely to influence the outcome of the trial. For a venire of a fixed size, the smaller the absolute disparity, the smaller the absolute impact will be. And, the absolute impact is the average difference per venire due to the underrepresentation.

The primary criticism leveled at the absolute disparity and absolute impact measures is that both ignore the size of the underrepresented group in the greater population. This can lead to apparently unfair results in some cases. ${ }^{39}$ For example, suppose that a jury wheel is composed of $45 \%$ women, when women make up $50 \%$ of the population. Although this seems like a lesser degree of underrepresentation than the total exclusion of African-Americans from juries in a community which is 5\% African-American, the absolute disparity is the same in both cases, namely five percentage points.

Some commentators and advocates raising jury composition challenges in situations where the underrepresented group is a small percentage of the population point out that use of absolute disparity or absolute impact can sanction the total exclusion of a small minority. Many have urged the adoption of comparative disparity as the appropriate measure of underrepresentation. ${ }^{40}$ Returning to the above examples, if $45 \%$ of the jury wheel is female, and women comprise $50 \%$ of the population, the comparative disparity is $10 \%$ (since the five percentage point absolute decrease is $10 \%$ of $50 \%$ ). On the other hand, if a 5\% African-American population is completely excluded from the jury wheel, the comparative disparity is $100 \%$.

Courts have been reluctant to adopt the comparative disparity standard, mainly because it can seem to overstate the degree of underrepresentation in

36. Id. at 64 (quoting the JSSA, 28 U.S.C. $\$ 1861$ (1988)).

37. Id. at 65 .

38. See infra text accompanying notes 76-77.

39. See Moultrie v. Martin, 690 F.2d 1078, 1082 (4th Cir. 1982); Foster v. Sparks, 506 F.2d 805, 835 (5th Cir. 1975); Beale, supra note 21, at 273-74; Kairys et al., supra note 21, at 793-94; Stone, supra note 21; Williams, supra note 21 , at $611-13$.

40. See David C. Baldus \& James W. Cole, Statistical Proof of Discrimination 153 (1980); Williams, supra note 21, at 613-14; Kairys et al., supra note 21, at 815 . 
the case of a very small minority. ${ }^{41}$ Thus, in the extreme case of only one member of a minority group in a community, if that person is not included in the jury wheel, the comparative disparity between the incidence of that minority on the jury wheel and in the population is $100 \%$. Yet few would argue that this implies the wheel does not provide a fair cross-section of the community or that the exclusion is probably the result of intentional discrimination. ${ }^{42}$

Despite the difficulties with comparative disparity, some courts have been persuaded that the use of absolute disparity or absolute impact is unfair when the underrepresented group comprises a small percentage of the population. One court has advocated "a flexible use" of the absolute and comparative disparity measures, noting that each may lead to unfair results in certain cases. ${ }^{43}$ But this seems to require that courts decide what the "fair" outcome is in advance and then choose the test which will dictate this result-hardly the way such tests are supposed to operate. In fact, one of the few courts to apply the comparative disparity measure did so not to a case involving a small minority as one might expect, but to a case involving a large minority. The rationale was that absolute disparity overstated the underrepresentation. ${ }^{44}$

No federal court has applied statistical decision theory in a fair crosssection challenge. ${ }^{45}$ As one court stated: "[A] defendant must demonstrate

41. See, e.g., United States v. Hafen, 726 F.2d 21, 24 (1st Cir.) ("the smaller the group is, the more the comparative disparity figure distorts the proportional representation"), cert. denied, 466 U.S. 962 (1984).

42. One of the few may be Cynthia Williams, who advocates comparative disparity and criticizes statistical significance tests because, as she states:

total exclusion of members of a small minority will result in fewer standard deviations than total exclusion of a larger minority since it is more likely that total exclusion of a small minority could occur by chance. This may be appropriate theoretically, but as a political matter it is important to develop statistics that allow accurate evaluation of the total exclusion of a minority group.

Williams, supra note 21 , at 613 (footnote omitted).

Williams goes on to advocate the use of comparative disparity, thus implicitly suggesting that the exclusion of a minority of one should be considered the equivalent of the exclusion of a group that comprises a large segment of the population. This makes no sense either politically or theoretically and is unlikely ever to encounter a warm reception in the courts.

Baldus and Cole recognize the "small number problem," and propose a flexible approach to the use of comparative disparity. BALDUS \& COLE, supra note 40, at 154 . However, unless the court is to decide on the merits of the case prior to choosing a measure, see infra text accompanying note 43, this approach would involve drawing an arbitrary line-below a certain population size comparative disparity would be unacceptable-which would necessarily lead to inequitable results in borderline cases.

43. Foster v. Sparks, 506 F.2d 805, 835 (5th Cir. 1975). See also State v. Ramseur, 524 A.2d 188, 234-37 (N.J. 1987) (refusing to choose among absolute disparity, comparative disparity, and SDT, and applying all three measures). In later cases, the Fifth Circuit has suggested that it might consider measures other than absolute disparity in cases where the group in question comprised less than $10 \%$ of the population (in which case absolute disparity could countenance total exclusion). See United States v. Butler, 615 F.2d 685, 686 (5th Cir. 1980); United States v. Maskeny, 609 F.2d 183, 190 (5th Cir.), cert. denied, 447 U.S. 921 (1980). But any attempt to allow different sorts of measures below some absolute line will lead to anomalous results in borderline cases.

44. Perkins v. Grammer, 664 F. Supp. 1280, $1283-84$ n.4 (D. Neb. 1987), aff'd, 838 F.2d 294 (8th Cir.), cert. denied, 487 U.S. 1220 (1988).

45. However, one federal court has urged its adoption, see infra text accompanying notes 63-67, and at least one state court has applied statistical significance in a fair cross-section challenge, People v. Buford, 
more than a statistically-significant disparity in order to prevail on a Sixth Amendment challenge; he must demonstrate a disparity which is legallysignificant in that it is "substantial." "46 The court went on to apply the absolute impact standard.

Once a measure has been chosen, a further question remains: What degree of underrepresentation according to that measure should be deemed "substantial"? Some of the courts that have adopted the absolute disparity measure have indicated that a less than ten percentage point disparity can never be substantial for the purposes of the fair cross-section guarantee. ${ }^{47}$ These courts relied on Swain v. Alabama, in which Justice White wrote for a 6-3 majority that "[w]e cannot say that purposeful discrimination based on race alone is satisfactorily proved by showing that an identifiable group in a community is underrepresented by as much as $10 \% . " 49$ But Swain was an equal protection challenge ${ }^{50}$ - purposeful discrimination is not an element of a fair cross-section challenge. The importation of the $S$ wain analysis seems to exemplify some courts' confusion of equal protection and fair cross-section requirements. ${ }^{51}$ Courts applying the absolute impact standard, as in Jenkins, ${ }^{52}$ have tended to be imprecise, relying on qualitative impressions of whether a given difference is substantial. ${ }^{53}$

\section{B. Equal Protection}

Many courts have failed to distinguish between fair cross-section and equal protection challenges to jury wheel composition with respect to the mathematical measures they apply. The most common measure in both situations has been absolute disparity. ${ }^{54}$ Several courts, however, have now endorsed SDT in the equal protection context. ${ }^{55}$ It seems intuitively

182 Cal. Rptr. 904, 909-10 (Ct. App. 1982).

46. United States v. Gerena, 677 F. Supp. 1266, 1274 (D. Conn. 1987); see also Ford v. Seabold, 841 F.2d 677, $684 \mathrm{n.5}$ (6th Cir.) (stating that although statistical significance may be relevant to equal protection challenge, it has no place in fair cross-section challenge), cert. denied, 488 U.S. 928 (1988).

47. See, e.g., United States v. Rodriguez, 776 F.2d 1509, 1511 (11th Cir. 1985); United States v. Clifford, 640 F.2d 150, 155 (8th Cir. 1981); United States v. Test, 550 F.2d 577, 587 (10th Cir. 1976).

48. 380 U.S. 202 (1965).

49. Id. at 208-09.

50. Id. at 204-05.

51. See Magid, supra note 17, at 1093-96; Melissa K. Gee, Note, A Jury Drawn from a Fair CrossSection of the Community-A Fading Memory?: People v. Sanders, 26 U.S.F. L. REv. 785, 792 (1992).

52. See supra text accompanying notes 33-37.

53. See United States v. Potter, 552 F.2d 901, 906 (9th Cir. 1977) (less than one person per average 23-person grand jury not substantial); United States v. Armsbury, 408 F. Supp. 1130, 1139 (D. Or. 1976) (.375 blacks and .450 Hispanics per average 75 -person venire not substantial).

54. See, e.g., Swain, 380 U.S. at 205-09 (1965); United States v. Sanchez-Lopez, 879 F.2d 541, 547 (9th Cir. 1989); United States v. Yazzie, 660 F.2d 422, 426-27 (10th Cir. 1981), cert, denied, 455 U.S. 923 (1982).

55. See, e.g., Alston v. Manson, 791 F.2d 255, $257-59$ (2d Cir. 1986), cert. denied, 479 U.S. 1084 (1987); Villafane v. Manson, 504 F. Supp. 78, 85-87 (D. Conn. 1980); see also Castaneda v. Partida, 430 U.S. 482, $496 \mathrm{n} .17$ (1977) (discussing application of SDT in equal protection case). 
appropriate to use SDT in the context of equal protection challenges, since "intent" is of primary importance in such cases. If one can show that the underrepresentation of a group is unlikely to be due to chance, in the absence of an alternative explanation, a fair presumption is that the disparity is due to discrimination. Commentators in favor of SDT have therefore generally advocated its use in equal protection challenges. ${ }^{56}$

There is, however, no rationale for applying different measures of underrepresentation in the fair cross-section and equal protection contexts that can survive close scrutiny. To establish an equal protection violation, a criminal defendant must show that he has been injured personally. In order to show injury of this kind, however, a defendant must in effect demonstrate that his right to a jury drawn from a fair cross-section of the community has been violated. This Section will argue accordingly that the fair cross-section inquiry is subsumed in the equal protection analysis. The courts that have adopted SDT for equal protection cases while rejecting it for fair cross-section cases seem to ignore the fact that proof of intent alone is not sufficient to make out a prima facie case and that proof of injury must also be presented.

A criminal defendant can challenge the composition of the jury wheel on equal protection grounds under two different theories, but under either one some showing of injury must be made. First, if the defendant is a member of the underrepresented group, he can argue that his equal protection rights have been violated by the underrepresentation of people from this group on the jury wheel. ${ }^{57}$ Alternatively, whether or not the defendant is a member of the underrepresented group, he can attempt to bring an equal protection challenge on behalf of members of the underrepresented group. ${ }^{58}$ In the former kind of

56. See Finkelstein, supra note 25; Stone, supra note 21.

57. See Underwood, supra note 5, at 728-36 (arguing that this theory is untenabie).

58. Whether the defendant can raise the equal protection rights of an underrepresented group has been a controversial subject. A number of cases discuss the standing of a defendant to assert that members of a group to which he does not belong have been excluded from jury service. The Supreme Court indicated in Castaneda, which involved an equal protection challenge to a grand jury, that the defendant may not have standing in such a case: "The defendant must show that the procedure employed resulted in substantial underrepresentation of his race or of the identifiable group to which he belongs." 430 U.S. at 494 (emphasis added). The implication is that a defendant is denied equal protection if he has been indicted by a grand jury (or, presumably, tried before a petit jury) that underrepresented members of his own group. It would seem to follow that, for example, a white defendant could not bring a challenge under the Fifth or Fourteenth Amendment if the State excluded African-Americans from his jury.

The precedents, however, are not uniform on this question. In Peters v. Kiff, 407 U.S. 493 (1972), the Supreme Court did allow a Fourteenth Amendment challenge under such circumstances. It has been argued, though, that the Court relied entirely on due process analysis, rather than on equal protection, and that it did so only because at the time the case arose the Sixth Amendment had not yet been incorporated as binding on the states by the Fourteenth Amendment. See United States v. Musto, 540 F. Supp. 346 (D.N.J. 1982). Thus, some courts have held that equal protection challenges by defendants who do not belong to the underrepresented group are barred by lack of standing. See Kevin W. Brown, Annotation, Standing of Criminal Defendant To Challenge, on Constitutional Grounds, Discriminatory Composition of Federal Grand Jury Where Defendant Is Not Member of Class Allegedly Excluded, 68 A.L.R. FED. 175, 182-84 (1984). Other courts have disagreed, arguing that Peters $v$. Kiff left room for such challenges, and that the language of Castaneda was restricted to the situation, as in that case, in which the defendant does happen to belong to the underrepresented group. United States v. Perez-Hernandez, 672 F.2d 1380, 1386 
case-a defendant asserting his own equal protection rights-the Supreme Court, in interpreting its decision in Castaneda, has made clear that discriminatory effect must be shown in addition to discriminatory purpose. ${ }^{59}$ In the latter kind of case-a defendant asserting the equal protection rights of members of the underrepresented group - the defendant must be granted thirdparty standing to raise the constitutional claims of others, and he must still show injury in fact. ${ }^{60}$

But, it is difficult to see how, if the defendant's fair cross-section right has not been violated, he can be said to have been discriminatorily affected or, alternatively, to have suffered injury in fact. ${ }^{61}$ The reasoning underlying the rejection of a fair cross-section challenge is that the degree of underrepresentation is too slight to have affected the defendant's trial. In this case, there has been no discriminatory effect or injury in fact and the defendant's equal protection challenge must also fail.

Hence, whatever level of underrepresentation is deemed substantial for purposes of the fair cross-section guarantee, the same hurdle must be cleared

(11th Cir. 1982).

The Supreme Court may have settled the issue in Powers v. Ohio, 111 S. Ct. 1364 (1991). The Court held, based on a theory of jus tertii, or third-party standing, that a white defendant could raise a Batson challenge to the exclusion of African-Americans from his jury. See Batson v. Kentucky, 476 U.S. 79 (1986) (holding that African-American defendant's right to equal protection of the laws has been violated if prosecution uses peremptory challenges to exclude African-Americans from jury on basis of race). A defendant may invoke third-party standing to assert the constitutional rights of others in situations in which he has suffered injury in fact and there are impediments preventing those whose rights have been violated from taking action to vindicate their own rights. See Powers, $111 \mathrm{~S}$. Ct. at 1370-73; Note, Standing To Assert Constitutional Jus Tertii, 88 HARV. L. REv. 423 (1974). While the Court's holding in Powers was restricted to Batson challenges, its reasoning would seem to apply with even more force to challenges to the composition of jury wheels. After all, while it may be unlikely that a prospective juror who was peremptorily challenged by the prosecution would sue to vindicate her right to serve on the jury, it is even less probable that a member of the community who has not been selected for the jury wheel would bring suit. If a group is discriminatorily underrepresented on a jury wheel, its rights will probably not be asserted unless a criminal defendant raises the matter. But see infra note 62 (citing class-action jury discrimination suits brought by members of underrepresented groups).

59. Duren v. Missouri, 439 U.S. 357, 368 n.26 (1979).

60. See supra note 58 .

61. That the defendant may have been convicted is not sufficient to show "injury in fact" for the purposes of third-party standing. There must be a "cause-and-effect relationship between the illegality and the alleged harm [which is] more than speculative." Powers, $111 \mathrm{~S} . \mathrm{Ct}$. at 1380 (Scalia, J., dissenting). The reasoning of the cases that find no violation of the fair cross-section guarantee is that, if the disparity is not sufficiently high, there is no reason to believe that the composition of the defendant's jury would have been substantially different had the wheel been representative of the community. Thus, the defendant has not suffered an injury due to the underrepresentation of a group. It would seem to follow that the defendant also has not met the injury-in-fact requirement of third-party standing. 
in an equal protection challenge. ${ }^{62}$ For this reason, we need only consider the appropriate measure of underrepresentation in a fair cross-section challenge.

Thus far, the Second Circuit has been the only court to recognize the inconsistency inherent in the use of different measures for fair cross-section and equal protection challenges. In Alston v. Manson, ${ }^{63}$ the court endorsed $\mathrm{SDT}$ in the equal protection context, finding that a sufficiently small probability that underrepresentation was due to chance establishes that the underrepresentation was "substantial," and meets the second prong of Castaneda. ${ }^{64}$ The court then seemed to realize that its use of SDT alone in equal protection challenges is difficult to reconcile with its use of absolute impact in the fair cross-section context. In particular, the court was disturbed by the apparent anomaly that the use of different measures could lead to success in an equal protection challenge but to failure in a fair cross-section challenge, even though the former has the additional requirement of demonstrating discriminatory intent. ${ }^{65}$ In dicta, the court indicated that the contradiction could be resolved by adopting SDT in Sixth Amendment challenges also, ${ }^{66}$ but offered no rationale for why SDT would be appropriate in those cases. Since discriminatory intent is not at issue in fair cross-section cases, the rationale from equal protection cases cannot carry over. The lack of any clear argument for the adoption of SDT is doubtless responsible for the fact that, despite the dicta in Alston, the Second Circuit has since reaffirmed the use of the absolute impact standard in fair cross-section cases. ${ }^{67}$

The Alston court was right to be concerned that different measures were being used to test the extent of the underrepresentation in equal protection and fair cross-section cases. But, although SDT may be the appropriate measure for raising the presumption of discriminatory intent, the defendant will only be able to show discriminatory effect or injury in fact if his fair cross-section rights have been violated, and it is not clear that SDT is the correct measure to test whether this violation has occurred. The next part of this Note will argue that neither SDT nor any of the other measures discussed thus far accurately reflects underrepresentation for the purposes of the fair cross-section guarantee.

62. This is true only if the party challenging the underrepresentation is a criminal defendant. Members of the underrepresented group could also bring an equal protection challenge on their own behalf, and in fact there have been a number of class actions of this type. Berry v. Cooper, 577 F.2d 322 (5th Cir. 1978); Blackwell v. Thomas, 476 F.2d 443 (4th Cir. 1973); Ford v. White, 299 F. Supp. 772 (S.D. Miss. 1969). Such actions properly ignore discriminatory effect on criminal defendants, focusing instead on the discriminatory effect on the underrepresented group. Thus, whether or not any defendant's fair cross-section right was violated would be irrelevant and the correct measure would be one, such as comparative disparity, that demonstrated the effect on the underrepresented group. See supra text accompanying note 24.

63. 791 F.2d 255 (2d Cir. 1986), cert. denied, 479 U.S. 1084 (1987).

64. Id. at 257-58.

65. Id. at 258-59.

66. Id. at 259.

67. See United States v. Biaggi, 909 F.2d 662, 677-78 (2d Cir. 1990), cert. denied, 499 U.S. 904 (1991); United States v. Rosario, 820 F.2d 584, 585 \& n.1 (2d Cir. 1987). 


\section{FLAWS IN ACCEPTED MEASURES OF UNDERREPRESENTATION}

All of the measures discussed thus far, whether applied by the courts or advocated by commentators, are flawed. This is not surprising since these measures have been selected for the wrong reasons-often because of ease of application, or because they lead to desired results independent of fair crosssection concerns. ${ }^{68}$ In order to see what is wrong with these measures and to arrive at a more appropriate measure of underrepresentation, it is necessary to examine the fair cross-section guarantee itself and attempt to determine what measure it dictates.

In deciding that a certain degree of underrepresentation does not constitute "substantial" underrepresentation, courts have noted that neither the Constitution nor the JSSA guarantees juries or jury panels that are mirror images of the community. ${ }^{69}$ The conclusion to be drawn, presumably, is that the defendant can have no complaint if a certain group is slightly underrepresented on the jury wheel, since the composition of the actual grand jury or petit jury may be no different from one chosen from a wheel which perfectly mirrors the community. But this argument proves too much. After all, grossly unrepresentative juries may on occasion be drawn at random from perfectly representative wheels. The relevant consideration must be that such an outcome is highly unlikely if the wheel is representative, but might be virtually certain if the wheel is sufficiently distorted. Thus, a proper fair crosssection analysis should focus on the degree to which the defendant's ex ante chances at a representative jury have been affected by underrepresentation of a group on the jury wheel.

Many courts have recognized that what the fair cross-section guarantee protects is the defendant's right to a fair chance at a representative jury. ${ }^{70}$ No court, however, has followed this thought to its logical conclusion and actually analyzed how the defendant's chances have been affected by the underrepresentation of a certain group on the jury wheel. Yet, as the language of the decisions themselves recognize, this is the analysis that must be undertaken if we are to determine whether the right to a jury chosen from a fair cross-section of the community has been violated. Something has been taken from the defendant in the case where a small minority has been largely excluded from the jury wheel-the defendant's a priori chances at a jury panel of various compositions have been altered, and the degree to which his chances have been altered is not immediately obvious from simply looking at the absolute disparity.

68. See, e.g., Williams, supra note 21 ; supra note 42.

69. See, e.g., Holland v. Illinois, 493 U.S. 474, 480 (1990) (stating that Sixth Amendment fair crosssection requirement does not assure representative jury).

70. See, e.g., Williams v. Florida, 399 U.S. 78, 100 (1970) (stating that juries must be selected so as "to provide a fair possibility for obtaining a representative cross-section of the community"). 
The flaw in the reasoning that leads to the absolute disparity test is that the courts take an ex post perspective. It is indisputable, as the Jenkins court argued, that an absolute disparity of two percentage points leads to a difference of only slightly more than one juror from the group per jury panel (of size sixty) on average. ${ }^{71}$ It is also true that the composition of the actual jury drawn by the defendant might have arisen even if the disparity had been corrected. What this argument fails to consider, however, is how the defendant's chances of different jury panels were skewed, ex ante, due to the distortion introduced by the missing group members.

The fair cross-section guarantee must dictate the choice of measure: to what extent were the defendant's chances altered by the underrepresentation of certain groups on the jury wheel? The mathematical tests that have been considered by the courts-absolute disparity, absolute impact, comparative disparity, and SDT-are relevant only insofar as they shed light on this fundamental question.

Accordingly, the courts have properly rejected comparative disparity and SDT for fair cross-section challenges, but they have not fared better by adopting absolute disparity or absolute impact. From this new perspective, consider the hard case for comparative disparity, namely the case of a minority group consisting of a single individual. ${ }^{72}$ Given a large jury wheel, the inclusion of a single minority member would not dramatically alter any particular defendant's chances of drawing that person for his jury. Hence, the defendant's fair cross-section right has not been violated if that minority member does not happen to be on the jury wheel. ${ }^{73}$ Yet, if there is only one member of the minority in the community, the comparative disparity is $100 \%$. A test that finds maximal underrepresentation in a situation in which the defendant's chances of jury composition are virtually unaffected cannot be a good one to apply generally.

Similarly, the question answered by SDT, while an interesting one, is not the appropriate one for a fair cross-section analysis. The probability that the composition of a jury wheel arose by random selection from the community is not directly related to the defendant's chances of drawing a jury of a certain composition. For example, consider a community that is exactly $50 \%$ female. If the jury wheel is sufficiently large, the chance of a wheel that is less than $49 \%$ female can be quite small. In fact, by imagining larger and larger jury wheels, the probability of any degree of underrepresentation arising by chance can be made arbitrarily small. But the size of the wheel, of such crucial importance for statistical significance, does not affect the defendant's chances

71. See supra text accompanying notes 33-37.

72. See supra text accompanying note 42 .

73. The defendant's rights have not been violated even if the minority member has been excluded due to intentional discrimination, although in that case the minority member could bring an equal protection challenge. See supra note 62 . 
of jury composition. The defendant's chances of an additional woman on a twenty-three-person grand jury, say, if the wheel were $50 \%$ rather than $49 \%$ female, are slight, independent of wheel size. ${ }^{74}$

The absolute disparity measure could only be reconciled with the defendant's right to a fair chance at a representative jury if a sufficiently small absolute disparity implied that the defendant's chances for juries of different compositions were not radically affected by the degree of underrepresentation. It is probably the case, however, that most courts underestimate the effect of even a small absolute disparity. Suppose, for example, that a community is $10 \%$ African-American and that only $5 \%$ of the jury wheel is AfricanAmerican. The absolute disparity of five percentage points is well within the range that has been rejected by the courts as too low to be considered "substantial." Consider, however, the probability that a twenty-three-person grand jury selected randomly from such a wheel would be all white. If the wheel is 5\% African-American, the probability of drawing an all-white grand jury is approximately $31 \% .{ }^{75}$ On the other hand, if the wheel had accurately reflected the 10\% African-American population of the community, the probability of an all-white grand jury would have shrunk to approximately $9 \%$. Ex ante, the defendant's chances of drawing a grand jury without any AfricanAmerican representation increased by twenty-two percentage points due to the underrepresentation of African-Americans on the jury wheel. Instead of less than one chance in ten that his grand jury would have no African-American members, the probability of such an outcome increases to almost one chance in three. Anyone who has ever bet on a horse race would have to regard the corresponding change in odds as "substantial." Similarly, if a petit jury of twelve were being drawn, the probability that it would be all white increases from $28 \%$ to $54 \%$ due to the underrepresentation on the wheel-an increase of 26 percentage points. ${ }^{76}$

The problem with absolute disparity (and similarly with absolute impact) is not just that courts underestimate the effect that a certain disparity will have on the defendant's chances of obtaining a representative jury. This problem could be solved by simply encouraging courts to draw the line at a lower level

74. Assuming, as usual, that the wheel is sufficiently large so that the drawing of the jurors will not have a substantial effect on the composition of the wheel. Under this assumption, if the percentage of women on the wheel is $50 \%$, the probability of 11 or fewer women being randomly selected for a 23person grand jury is also $50 \%$. If the percentage of women on the wheel decreases to $49 \%$, the probability of 11 or fewer women being selected increases slightly to 54\%, regardless of how large the wheel is.

75. This figure is easily calculated. The probability that any one juror drawn is white is .95 (or $95 \%$ ), so the probability that all 23 drawn are white is .95 raised to the twenty-third power or .31 . This calculation assumes that the wheel is sufficiently large that the percentage of whites remaining on the wheel is substantially unaffected as each juror is drawn.

76. This calculation assumes that the jury is drawn by random selection from the jury wheel. This, of course, ignores the effect of peremptory challenges that intervene between the random selection of the venire and the empaneling of the final jury. However, since race considerations should play no role in this process, Batson v. Kentucky, 476 U.S. 79, 88-89 (1986), we need not consider the peremptory challenges for our purposes. 
of absolute disparity than they have been willing to do thus far. Rather, as in the case of comparative disparity and SDT, absolute disparity is measuring the wrong thing. While the absolute disparity is related to defendant's chances of a representative jury, other factors are also important. The critics of absolute disparity have correctly pointed to the measure's insensitivity to the size of the underrepresented group in the population. Although it is not obvious, it turns out that the size of the group does affect the defendant's chances of obtaining a jury which accurately represents that group. ${ }^{77}$ Since absolute disparity does not take the size of the group into account, it cannot be the correct measure to use in fair cross-section cases.

The use of a measure that would assure criminal defendants a fair chance at juries that are representative of their communities, in addition to being consistent with the fair cross-section guarantee, would have profound practical effects. In holding that five-member juries violated the Sixth Amendment, the Supreme Court surveyed various studies indicating the significant effects that the presence or absence of minority viewpoints can have on jury verdicts. ${ }^{78}$ Furthermore, a strong correlation exists between the presence of minority groups on the jury and the verdict delivered. ${ }^{79}$ Studies show that jurors tend to be more sympathetic to defendants of their own race, and other factors such as the race of the victim and the crime charged also can lead to different verdicts depending on the race of the jurors. ${ }^{80}$ In short, there is strong empirical evidence for the proposition that jury verdicts are influenced by the representation of minority groups on the jury. A criminal defendant whose chances at a representative jury have been undermined due to the underrepresentation of one or more community groups on the jury wheel may rightly assert that his right to a jury drawn from a fair cross-section of the community has been violated and that this violation may well affect the verdict in his case. ${ }^{81}$

\section{A New Measure for FaIr Cross-Section CaSes}

None of the four measures discussed above adequately tests the extent to which a defendant's ex ante chances have been affected by the underrepresentation of a group on the jury wheel. There is reason, then, to

77. See infra p. 1935.

78. Ballew v. Georgia, 435 U.S. 223, 233, 236-38 (1978).

79. Sheri L. Johnson, Black Innocence and the White Jury, 83 MiCH. L. REv. 1611, I621-22, 1634-35 (1985); Nancy J. King, Postconviction Review of Jury Discrimination: Measuring the Effects of Juror Race on Jury Decisions, 92 MiCH. L. REV. 63, 80-85 (1993).

80. Johnson, supra note 79 , at 1634-35.

81. But see Underwood, supra note 5, at 774 ("The harm inherent in jury discrimination does not depend on empirical studies about the relationship between jury composition and verdicts. ... [Jury discrimination] is wrong because it excludes people by reason of race from participating in a fundamental institution of American government."). 
search for a measure that more accurately captures these fair cross-section concerns. In the example of a $10 \%$ African-American population with only $5 \%$ representation on the jury wheel, we calculated the effect of the underrepresentation on the defendant's chances of drawing a jury from which the group in question was completely excluded. ${ }^{82}$ The increase in the probability of total exclusion might be a reasonable measure of the change in the defendant's chances of a representative jury in the case when the group in question was a relatively small minority. In that case, only a small number would be expected to be drawn for any given jury, even from a representative wheel.

When the group makes up a large percentage of the community, however, this approach will not yield the correct result. For example, suppose that women make up $50 \%$ of the community, but only $30 \%$ of the jury wheel. The probability that any given twenty-three-person grand jury, for instance, would contain no women is very small. Consequently, the increase in the probability of an all-male jury is small, despite the fact that women clearly seem to be substantially underrepresented in this case. ${ }^{83}$ This is because we have again turned our backs on the question of how the defendant's ex ante chances of an unrepresentative jury in general have been affected, answering instead the question of how his chances of obtaining a grossly unrepresentative jury have been affected.

There is no reason to restrict ourselves to consideration of only the extreme case of total exclusion of the underrepresented group. In the above example, since the expected number of female grand jurors would be 11.5 if the wheel accurately mirrored the 50\% female population, any grand jury containing eleven or fewer women would underrepresent women. And in the case in which the wheel is unrepresentative, the defendant's chances of drawing certain sorts of unrepresentative juries is increased dramatically from what they would be with a representative wheel. For example, given that the wheel is only $30 \%$ female, there is a greatly increased chance that the defendant's grand jury would contain six or fewer women. If the wheel were $50 \%$ female the probability of drawing six or fewer women would be only $1.7 \%$. By contrast, the probability of drawing six or fewer women from a $30 \%$ female wheel jumps to $44 \%$. Because of the underrepresentation on the wheel, the defendant's risk of drawing a jury with six or fewer women has increased by 42.3 percentage points $(44 \%-1.7 \%)$. The increased risk is yet more pronounced if we consider the defendant's chances of drawing a jury with

82. See supra text accompanying notes 75-76.

83. If the wheel is $50 \%$ female, the probability of random selection yielding an all-male 23-person grand jury is $1.19 \times 10^{-7}$ On the other hand, if the wheel is only $30 \%$ female, the probability rises to 2.74 $\times 10^{-4}$. Although the defendant's chances of an all-male jury have been multiplied by more than 2000 , it still remains a highly unlikely event. We cannot say that defendant's chances of an all-male jury have been substantially affected when there is virtually no chance under either scenario that he will wind up with one. 
eight or fewer women on it-in this case underrepresentation on the wheel increases the probability from $10.5 \%$ to $77.1 \%$, a difference of 66.6 percentage points.

To measure fully, then, how the defendant's chances of drawing an unrepresentative jury have been affected by the underrepresentation of women, for example, on the jury wheel, we only begin by considering the increase in the probability of drawing juries with no women on them. For a complete picture we must go on to calculate the increase in the probability of drawing a jury with one or fewer women, two or fewer women, three or fewer women, and continue in this manner until we have calculated the increase in the probability of drawing a jury with eleven or fewer women. ${ }^{84}$ These calculations will yield twelve numbers, representing the defendant's increased risk of unrepresentative juries at various degrees of underrepresentation. The largest of these numbers is critical, representing the greatest increased risk of an unrepresentative jury that the defendant is exposed to due to the underrepresentation of women on the jury wheel. In this example, the probability of drawing a grand jury with nine or fewer women on it shows the greatest increase, going from $20.2 \%$ when women are accurately represented on the wheel to $88 \%$ when they are underrepresented. This Note will refer to the difference of 67.8 percentage points as the defendant's "disparity of risk" of drawing an unrepresentative jury in this case.

In general, to determine the effect that the underrepresentation of a given group has on the defendant's ex ante chances of an unrepresentative jury, calculate the disparity of risk as follows. First determine the expected number of members of the group in question per jury if the drawing were done at random from a representative wheel. For each integer, $n$, strictly less than this expected number, calculate the probability that a jury would have $n$ or fewer group members on it, first, if the wheel were representative, and second, given the actual underrepresentation. ${ }^{85}$ For each $n$, of course, the second probability will be larger. The difference between these two probabilities is a measure of the change in the defendant's chances of drawing a jury with $n$ or fewer group members on it. ${ }^{86}$ The greatest probability increase as $n$ runs from zero up to

84. Juries with 12 women no longer underrepresent women since the expected number per grand jury based on the percentage of women in the population is 11.5.

85. Given a wheel sufficiently large that the percentage of group members does not change significantly as jurors are drawn, these probabilities can be calculated using the binomial distribution. See supra note 26.

86. This quantity is related to "relative risk"- a measure often used in biostatistics and epidemiology to measure the degree of association between a disease $D$ and an antecedent condition $A$. FINKELSTEIN \& LEVIN, supra note 26, at 1-2; Kaye, supra note 24, at 279 (proposing use of relative risk-termed "relative chance" in this context-which would measure more accurately than comparative disparity the degree to which probability of jury service has dropped for members of an underrepresented group). The relative risk of contracting $D$ is defined as the ratio of the probability of contracting $D$ when $A$ is present to the probability of contracting $D$ when $A$ is absent, i.e., $P(D \mid A) / P(D \mid \neg A)$.

By analogy, we could define the relative risk of a defendant drawing a jury with $n$ or fewer group members on it (denote this event by $J_{n}$ ), depending on whether there was underrepresentation on the wheel 
(but not including) the expected number of group members is defined to be the defendant's disparity of risk. ${ }^{87}$ In effect, disparity of risk measures the amount by which underrepresentation on the wheel increases the defendant's risk of drawing an unrepresentative jury. ${ }^{88}$

Why choose the greatest probability increase to define the disparity of risk rather than, say, the average of the different probability increases? The reason is that if the probability of a certain kind of unrepresentative jury increases substantially, then the defendant is exposed to that additional risk-there does not appear to be any reason to downgrade it simply because the increased risk of a different sort of injury is less dramatic. Furthermore, we need not be concerned that disparity of risk will overstate the injury to defendant. The increase in the probability of drawing a jury with $n$ or fewer group members will only be a large number if the probability of such a jury given the underrepresentation is itself large-i.e., if there is a real likelihood that the defendant will actually draw such a jury. As an illustration, consider the case of a twenty-three-person grand jury drawn from a jury wheel that completely excludes a group comprising $50 \%$ of the population. In this case, since the group is totally excluded, the probability that the grand jury will have no jurors from the group is $100 \%$. If the wheel were representative, the probability that the grand jury would contain no one from the group would be virtually zero. ${ }^{89}$ Hence, the probability that the defendant will draw no grand jurors from the group will have increased by almost 100 percentage points due to the underrepresentation. In this extreme case, we know that the defendant will in

(denote underrepresentation on the wheel by $U W$ ), as

$P\left(J_{n} \mid U W\right) / P\left(J_{n} \mid \neg U W\right)$

In terms of this notation, the change in the defendant's chances, as defined in the text, can be written as $P\left(J_{n} \mid U W\right)-P\left(J_{n} \mid \neg U W\right)$.

It is preferable to subtract the two values in this situation rather than to take their ratio, because the latter approach does not take into account the magnitudes of the probabilities. For example, consider two cases. In case $A$, the defendant's risk of a jury containing $n$ or fewer group members increases from $30 \%$ to $90 \%$ due to underrepresentation. In case $B$, the defendant's risk of drawing a jury of $n$ or fewer group members increases from $1 \%$ to $3 \%$. The defendant has suffered much greater injury in case A since instead of it being rather unlikely that he would draw a jury with $n$ or fewer group members (less than one chance in three), such an outcome has become highly probable due to the underrepresentation ( 9 chances in 10 ). On the other hand, in case $B$, although his risk of drawing a jury containing $n$ or fewer members has increased from one chance in 100 to three chances in 100, actually drawing such a jury remains highly unlikely. Subtracting the probabilities bears out this intuition, yielding a difference of $60 \%$ in case $A$ and a much smaller difference of $2 \%$ in case B. Taking ratios, by contrast, would imply that $\mathrm{A}$ and $\mathrm{B}$ are equivalent, since the relative risk is 3 in both cases.

87. Using the symbols defined in note 86 , supra, and denoting the expected number of group members that would be drawn for a jury if the wheel were representative by $E$, the disparity of risk is given by:

$$
\max _{0 \leq n \leq E}\left\{P\left(J_{n} \mid U W\right)-P\left(J_{n} \mid \neg U W\right)\right\} \text {. }
$$

88. The Supreme Court considered something like disparity of risk in Ballew v. Georgia, 435 U.S. 223, 236-37 (1978) (holding five-member juries unconstitutional). Assuming that a minority viewpoint was shared by $10 \%$ of the community, the Court calculated the change in the percentage of juries that would have either zero minority members or two minority members if the size of the jury decreased from 12 to 6.

89. $1.19 \times 10^{-7}$. 
fact draw a grand jury with no group members on it and that this would almost certainly not have happened but for the underrepresentation. The defendant's increased risk of a grand jury with no group members is almost 100 percentage points, and this is the value of the disparity of risk as we have defined it. The fact that the probability of drawing a grand jury with eleven or fewer group members has increased by only fifty percentage points does not seem to be particularly relevant in this case and should not affect our measurement of the increased risk faced by the defendant.

Disparity of risk agrees with our intuitions about how a measure of the change in the defendant's chances of drawing an unrepresentative jury should behave. If $n$ is very close to (but less than) the expected number of group members on a jury given a representative wheel, the change in the probability of drawing a jury with $n$ or fewer group members due to underrepresentation may not be very large. This is because, since $n$ is close to the expected number, there is a reasonably high likelihood that a jury with $n$ or fewer members will be drawn, even if the wheel is representative. As $n$ gets somewhat further from the expected number, the change in the probability of drawing a jury with $n$ or fewer group members grows. This is because when $n$ is in such a range, this outcome would be very unlikely with a representative wheel, although it would be quite probable given the underrepresentation. If, although underrepresented, the group is nevertheless substantially represented on the wheel, then as $n$ gets still farther from the expected number it will become unlikely that $n$ or fewer group members would be drawn even given such underrepresentation. In this case, the change in the probability of drawing $n$ or fewer group members due to the underrepresentation will begin to decline. In the typical case, the change in probability of drawing $n$ or fewer group members will peak, and give rise to what we call the disparity of risk, when $n$ is one or two less than the expected number of jurors. In such a case, the disparity of risk corresponds to the change in the defendant's ex ante chances of drawing a jury which underrepresents the group in question by more than one or two jurors. If, however, the group in question is almost totally excluded from the wheel, then the probability of drawing $n$ or fewer group members will not decline so rapidly as $n$ gets further from the expected number, and the change in probabilities will peak further away from the expected number and at a larger value. Thus, disparity of risk takes into account how serious the underrepresentation on juries is likely to be and yields a larger value if the jury is likely to be underrepresented by several group members, rather than by just one or two group members.

To see how disparity of risk would work in the case of a small minority, we can apply it to a previous example. In the case of a twenty-three-person grand jury, if African-Americans make up $10 \%$ of the community, the expected number of African-Americans per grand jury would be 2.3. Suppose that the wheel were representative of the community, i.e., were also $10 \%$ African- 
American. In that case, the probability that a randomly selected grand jury would contain no African-Americans is $8.9 \%$; the probability that it would contain one or fewer African-Americans is $31.5 \%$; and the probability that it would contain two or fewer African-Americans is $59.1 \%$. If the wheel were only 5\% African-American, however, the probabilities increase respectively to $30.7 \%, 67.9 \%$, and $89.5 \%$. The greatest increase occurs in the probability of drawing a grand jury with one or fewer African-Americans, yielding a disparity of risk of 36.4 percentage points $(67.9 \%-31.5 \%)$.

Disparity of risk is not open to the criticisms that have been leveled at the measures currently used by courts. This is not surprising, since those criticisms were based on the fact that the measures did not always accurately reflect the underrepresentation that the fair cross-section guarantee was concerned with in all cases: The criticisms generally took the form of an example in which substantial underrepresentation seemed self-evident, but the measure showed only a small disparity, or, conversely, an example in which the measure showed a large disparity despite seemingly minimal underrepresentation. Disparity of risk, on the other hand, is designed to capture fair cross-section concerns and thus is a nonarbitrary measure of difference.

The charge most frequently leveled at the absolute disparity measure is that it does not take the size of the minority into account. Disparity of risk, however, agrees with our intuitions that the same degree of absolute disparity is cause for greater concern when a small minority is being substantially underrepresented. As noted above, if a $10 \%$ African-American population has a representation of only $5 \%$ on the jury wheel, the disparity of risk equals 36.4 percentage points. On the other hand, if a group makes up $50 \%$ of the population but only $45 \%$ of the jury wheel, an absolute disparity of five percentage points once again, the disparity of risk comes out to only 18.9 percentage points.

Courts have been unwilling to adopt comparative disparity because it could exaggerate the underrepresentation of a small minority. The extreme case is, of course, a minority of one. To see the result dictated by disparity of risk in this case, suppose that the jury wheel contained 5,000 names. If the "group" member were on the wheel, the probability that he would nevertheless fail to be randomly selected for a twenty-three-person grand jury is $99.5 \% . .^{90}$ If the group member were not on the wheel, the probability that he would not be selected is, of course, $100 \%$, yielding a difference of only .5 percentage points. Since there is only a minimal change whether or not the wheel contains the minority member, the omission of the minority member would not be found to rise to the level of substantial underrepresentation using disparity of risk.

90. To calculate the probability exactly, multiply the probability that the group member is not the first juror selected, 4999/5000, times the probability that he is not the second juror selected, 4998/4999, times the probability that he is not the third juror selected, 4997/4998, and continue in this manner until all 23 jurors have been selected. 
Finally, SDT has been found wanting in the fair cross-section context because statistical significance does not necessarily translate into legal significance. Disparity of risk is not vulnerable to this criticism. If the defendant's chances were substantially affected by the underrepresentation, the underrepresentation might or might not be statistically significant. ${ }^{91}$ However, it would necessarily be legally significant precisely because the ex ante chances that have been affected are what the fair cross-section guarantee protects.

It remains to be determined what degree of underrepresentation, according to disparity of risk, constitutes substantial underrepresentation under the second prong of the Duren and Castaneda tests. If disparity of risk is adopted, this determination must be made by the courts. Regardless of where the line is drawn, however, we can be assured that, unlike a test using one of the four measures currently being debated, a test incorporating disparity of risk would not lead to anomalous results-all those cases that fall over the line impinge on the defendant's ex ante chances, and consequently on his fair cross-section rights, to a greater degree than those that fall below the line.

Since a number of courts that have adopted the absolute disparity test have suggested a ten-percentage-point line, we might examine what this would imply for disparity of risk. Unlike absolute disparity, disparity of risk does depend on the size of the underrepresented group. For a group constituting a relatively large percentage of the population, say $50 \%$, an absolute disparity of ten percentage points corresponds to a disparity of risk of thirty-seven percentage points. If courts used a thirty-seven percentage point disparity of risk test, some of the cases discussed previously in Part III, which were rejected for failure to demonstrate substantial underrepresentation, would now clear that hurdle, while others would be unaffected. For example, in United States v. Goff, ${ }^{92}$ the court held that an absolute impact of 1.4 grand jurors, based on an absolute disparity of 6.17 percentage points (the group comprised $10.51 \%$ of the community and $4.34 \%$ of the jury wheel) did not rise to the substantial level..$^{93}$ The disparity of risk, however, is 44.9 percentage points-well above our hypothesized thirty-seven percentage point line. On the other hand, the 2.15 percentage point absolute disparity (between $5.45 \%$ and $3.3 \%$ ) in United States v. Jenkins, ${ }^{94}$ corresponds to a disparity of risk of only 18.7 percentage points, which would still not meet our revised test.

91. The underrepresentation might not be statistically significant, even though the defendant's chances would be substantially affected, if the jury wheel were very small. In that case, an unrepresentative composition would not be so improbable and hence would not be statistically significant. In practice, since jury wheels tend to be quite large, any case in which the wheel would be so unrepresentative as to substantially affect the defendant's chances would also pass the test of statistical significance.

92. 509 F.2d 825 (5th Cir.), cert. denied, 423 U.S. 857 (1975).

93. Id. at 827.

94. 496 F.2d 57, 64 (2d Cir. 1974); see supra text accompanying notes 33-37. 
As a number of commentators have pointed out, a ten-percentage-point absolute disparity test sanctions the total exclusion of any minority that forms less than $10 \%$ of the population. This is not the case for a thirty-seven percentage point disparity of risk test. In fact, total exclusion of any minority that formed $2 \%$ or more of the population would lead to a disparity of risk of greater than thirty-seven percentage points. Although minorities comprising less than $2 \%$ of the population could be totally excluded even under this test, this outcome is not necessarily a cause for concern. After all, if a minority were extremely small, its total exclusion would not substantially affect the defendant's ex ante chances of drawing a representative jury. If members of that minority feel that they are victims of discrimination, they could pursue a class action equal protection challenge in which a defendant's disparity of risk would not be at issue. ${ }^{95}$

Courts need not, however, adopt a thirty-seven percentage point line for the disparity of risk measure simply because this figure corresponds to a ten percentage point absolute disparity in a certain situation. Disparity of risk represents the increased risk of the defendant's drawing an unrepresentative jury due to underrepresentation on the jury wheel. Courts may find that an increased risk significantly lower than thirty-seven percentage points substantially affects a defendant's chances. As noted above, this question must be left to the courts to determine, preferably courts armed with accurate data concerning the impact that a given degree of underrepresentation would have on the defendant's right to a jury chosen from a fair cross-section of the community.

\section{CONCLUSION}

The appropriate measure of underrepresentation in Sixth Amendment/JSSA challenges is dictated by the nature of the fair cross-section guarantee itself. Since the defendant is entitled to a fair chance at a representative jury, we should calculate to what extent this chance has been altered by the underrepresentation of a particular community group on the jury wheel. The measures of underrepresentation that have been used or advocated thus far fail to capture the essence of the fair cross-section guarantee and hence lead, in certain situations, to results inconsistent with that guarantee.

The same measure of underrepresentation should be used to analyze equal protection challenges under the Fifth or Fourteenth Amendments. While the use of SDT may be appropriate to raise the presumption of discriminatory intent, the defendant must also show discriminatory effect in the form of injury to himself. If the defendant's jury has been drawn from a fair cross-section of the community, there has been no injury.

95. See supra note 62 . 
The fact that the underrepresentation is found to be substantial, however, does not end the inquiry. The second prong of the Duren or Castaneda tests may have been met, but two further prongs must be satisfied for either test. Furthermore, the three prongs taken together only serve to establish a prima facie case in either fair cross-section or equal protection challenges. The government may be able to rebut by demonstrating a significant state interest served by the underrepresentation or by disproving the inference of intentional discrimination respectively. Too many challenges, however, have been rejected at an early stage simply because the numbers have not passed an inappropriate test for the second prong of the prima facie case. 